BIO Web of Conferences 4, 00007 (2015)

DOI: $10.1051 /$ bioconf/20150400007

(C) Owned by the authors, published by EDP Sciences, 2015

\title{
Evolutionary origins of hydrothermal vents metazoans
}

\author{
Sarah Samadi ${ }^{\mathrm{a}}$ \\ Institut de Systématique, Évolution, Biodiversité (ISYEB - UMR 7205 - CNRS, MNHN, UPMC, \\ EPHE), Muséum national d'Histoire naturelle, Sorbonne Universités, 57 rue Cuvier, CP. 26, \\ 75005 Paris, France
}

\begin{abstract}
The discovery of the oases associated with hydrothermal vents in the deep sea, is probably the most fascinating discovery of oceanography of the last century. In this habitat, contrary to all expectations, a thriving development of unknown organisms was observed. At that time the knowledge about the deep sea organisms was very scarce and the accepted hypotheses about their evolutionary origins, their physiology or their ecology were very speculative. Almost forty years later, exploration of the deep-sea realm, but also of paleontological data together with the improvements in the phylogenetic methods, allowed the rejection of the hypothesis of an evolutionary history cut off the rest of the marine realm.
\end{abstract}

\section{Life in the deep sea: Knowledge is recent}

In the thirty years after the discovery of the deep-sea oases associated with hot vents much of the research efforts of the marine biologists have been devoted to this exceptional environment and its inhabitants. However, when the hot vents have been discovered, the deep-sea realm was still poorly known. At this time, most of the available hypotheses about the functioning of deep sea ecosystems, or about the physiology or the evolutionary origins of the organisms were very speculative. In this historical context, I selected three hypotheses which I feel have played a major role in the analysis of the diversity of hot vents' organisms and their evolutionary origins.

\subsection{The azoic hypothesis}

In the mid-19 $9^{\text {th }}$ century, Edward Forbes noticed that life becomes impoverished with depth in the Aegean Sea and by extrapolation he proposed the azoic hypothesis according to which there was no life in the deep sea [1]. In the meantime, the discovery of organisms attached to submarine cables, notably mollusks and coral, at depths around 2000 meters demonstrated that this hypothesis was false [2]. The second half of the $19^{\text {th }}$ century brought the first significant set of data thanks to large naturalistic expeditions. Among them, the circumnavigations of the HMS Challenger (from 1872 to 1876) provided one of the most important corpuses of knowledge. These circumnavigations covered a wide geographic area but their importance also lied on the dynamism of the network of collaborators who studied the

\footnotetext{
${ }^{\text {a }}$ Corresponding author: sarah.samadi@mnhn.fr
}

This is an Open Access article distributed under the terms of the Creative Commons Attribution License 4.0, which permits unrestricted use, distribution, and reproduction in any medium, provided the original work is properly cited. 
samples and published the results in a series of dedicated volumes, coordinated by Sirs Murray and Thompson. A large part of the results were taxonomic descriptions, mostly of new species but also some new genera and families. The coordination of the publications of the results also allowed generalization not from isolated observations but from accumulation of facts. Notably, the sampling of all kinds of animals at every explored depth worldwide provided robust grounds to reject the azoic hypothesis.

This accumulation of facts also provided new hypotheses both about the evolutionary origins of the organisms and about the functioning of ecosystems. For example, based on the classification of the newly described species into higher rank categories, Thompson [3] suggested that the abyssal organisms must have an evolutionary origin in the shallow fauna: "It seems probable for several reasons, the most obvious of these being that no Classes nor Orders, and but few Families and Genera, are met with in the abyssal regions which do not likewise occur in shallower water, that the original direction of the migration of marine animals is from the shore seawards". Similarly, the idea that the deep-sea fauna is slow evolving, and that its study opens a window on an "antique" fauna, is rooted in the consideration of the results of these exploration as a whole: "The discovery of the abyssal fauna, accordingly, seems to have given us an opportunity of studying a fauna of extreme antiquity, which has arrived at its present condition by a slow process of evolution from which all causes of rapid change have been eliminated" [3].

From the same set of data, the opposite hypothesis was however also formulated by Moseley [4]: "How is it that the general absence of ancient forms from the deep sea is to be accounted for? It is hardly probable that the struggle for existence in the great depths is very severe. The fact that so helpless an animal as a Pycnogonid can grow to a length of two feet points to the existence of easy conditions of life. Even if the struggle in the deep sea were as great as in shallow water we might have expected that it would extinguish these different forms from those which it exterminated near the shores. It seems on the whole probable that the deep sea may have been entirely devoid of life during the earlier geological epochs. The modifications existing in deep-sea animals as adaptations to their special modes of life are not much more important than those exhibited by animals inhabiting caves of comparative recent origin, such as Proteus or those living in the deep waters of the large lakes of Europe, which are also of no great antiquity, such as the air-breathing water-snails, which, from the necessities of deep-water life, have adapted their lungs to aquatic respiration. A long time has not therefore been required for these modifications to take place".

In the same paper, Moseley [4] also suggested that the nutrition of deep-sea organisms relies on the rain of organic debris falling from the surface to the bottom, from land seaward. This hypothesis derives from the lower abundances of deep-sea animals observed at deeper sites but also on the absence of light and thus of living plants and the presence of plant remains on which animal were observed to feed on.

\subsection{Antiquity of deep-sea fauna}

As underlined by Menzie \& Imbrie [5]: "A recurring theme in the works of many marine biologists has been the view that the abyssal depths of the sea have offered an environment especially favorable for the conservation of archaic types of life." These discussions probably primarily relied on the fact that deep-sea expeditions brought back some organisms that were known only from fossils data. For example during the Challenger Expedition a unique specimen of a sponge described by Sollas in 1888 as Pleroma turbinatum was dredged from $573 \mathrm{~m}$ off the Fiji Islands. This specimen with a second specimen attributed to a species actually recognized as Pleuroma torquilla, were the only known material of living Pleromidae (known chiefly from fossils). More recently, the exploration of the deep seamounts notably in New Caledonia revealed many other lithistid sponge species that were closely related to Mesozoic fossils from the late Cretaceous of Europe [6, 7]. Menzie \& Imbrie [5] used a comparative approach to discuss this hypothesis. They compared the depth-age distribution of several taxa for which fossil records exist at least back to the Tertiary and concluded that the deep sea does not accommodate 


\section{ORIGINS}

significantly more archaic forms than shallow water and that much of the debate is resolved simply by clarifying the terms "ancient" and "deep."

The hypothesis of a slow evolutionary rate allowing the conservation of archaic forms was also rooted in the perception of the deep-sea as a monotonous, poorly productive, and buffered environment. Under this view, the deep sea was supposedly poorly affected by environmental changes such as sea level rises and falls or climate fluctuations. Based on this hypothesis, Zenkevitch \& Birstein [8] rejected the conclusions of Menzie \& Imbrie [5]. They pointed at the fact that the fossil record for deep-sea habitats is scarce and that thus restricting the analysis only to taxa present in the fossil records biased the conclusions. Their approach is based on "a taxonomic analysis of animal groups at present dominant in great oceanic depths" with the following argumentation: "certain groups are richly represented by species and genera in the deeps and have but few, if any, representatives in shallow waters. The great diversity of representatives of these groups in deep waters may be interpreted in two ways: they are either remnants of a fauna dominant in shallow-waters in ancient times, or they have had enough time during their stay in abyssal depths to evolve numerous species and genera. No other alternative seems possible. In both cases these groups must be of very ancient origin since their dying out in shallow waters and descent into great depths, as well as the advanced process of speciation, must have extended over a very long period. In our opinion no formation of major taxonomic units occurred under abyssal conditions: there was simply an adaptive radiation into species and genera. It appears therefore that those higher taxonomic units, mainly, or entirely confined to great oceanic depths, should be most correctly regarded as relicts which in former times lived under the favourable conditions of the shallow seas and were displaced by relatively young and more progressive groups."

Clarke [9] highlighted marked trends in the relative composition and characteristics of shallow and deep molluscan fauna: "(1) marked differences in the relative composition of the fauna of the two areas in terms of frequency of species and of individuals belonging to certain higher categories; (2) major shifts in the feeding-type composition of the fauna of the two regions; (3) divergence of average population densities; and (4) significant differences in the average size, weight and shell thickness between the mollusks of both areas." However, he noted that almost no higher taxonomic ranks were specific to the deep sea and also that there were no specific feeding types associated with deep-sea life. In addition, based on the low abundancies and small size of most organisms, he suggested that the conditions were not favourable for a thriving development of life. Using this reasoning he thus concluded: "In fact, on the basis of our present knowledge concerning which feeding types are likely to be successful in the abyssal environment, one may speculate that if the whole abyssal molluscan fauna were wiped out today, in a few million years re-population from shallower regions would produce a fauna which would be very much like the present one."

\subsection{Food-input, a major driver of the adaptation to deep-sea life?}

Since the pioneering $19^{\text {th }}$ century expeditions, food limitation has been pointed out as a major factor explaining biogeographical patterns of deep-sea biodiversity. Food input is still often considered as the main driver in the evolution of deep-sea organisms. Corrigan et al. [10] (2014) explored the hypothesis according to which the increased speciation rate of cetaceans during the Eocene/Oligocene offered the opportunity for the radiation in the deep sea of a lineage of scavenging amphipods. In this study, the opening of a new ecological niche associated with a new feeding resource is hypothesized as the factor explaining the evolutionary radiation of Lysiassanoidea. This example illustrates how the specific biological traits of deep-sea organisms are interpreted as adaptation to the conditions that are supposed to be limitative for the development of life. The main characteristics of deep-sea habitats that are usually considered as requiring specific adaptations are low temperatures, obscurity, high pressures and, as already underlined above, limitation of food inputs. 
However, comparative data allowing such adaptive conclusions are often lacking. For example, many deep-water fishes, crustaceans and cephalopods share a low metabolic rate compared to their shallower relatives. This biological trait has often been interpreted as an adaptation to the low food and oxygen availability characteristic of deep-sea habitats. However, a comparative approach falsified this hypothesis and suggested for example that this shared characteristic rather results from a relaxation of the selection pressure from predators [11].

\section{Hot vents in the deep-sea: Oases in an oligotrophic environment}

\subsection{Discovery of deep-sea oases associated with hot vents}

In the $20^{\text {th }}$ century explorations have continued with the help of new instruments. In May 1905, the first General Bathymetric Charts of the Ocean was published. In 1925 the echosounder invented by RA Fessenden was used for the first time for bathymetric mapping on the German RV Meteor. After WWII, exploration has continued at abyssal and hadal depths (2,000 to 10,000 m). In the 1950's, oceanographers have started using submersibles. All these technological improvements provided new data but did not fundamentally revolutionize the perception of the deep-sea habitats until the first discovery of a hot vent in 1977 in the Galapagos. Unexpectedly, a highly productive ecosystem was discovered associated with these black smokers spewing hot and mineral-rich fluids at a depth of about $2.5 \mathrm{~km}$. This dense community was first supposed to rely on organic matter transported by the convection cells generated by the vent system [12].

The first vent cruise organized by biologists in 1979 evidenced the presence of free-living chemosynthetic bacteria, suggesting that this community did not primary rely on the food input from the surface $[13,14]$. The study of the abundant gutless worms Riftia pachyptila first attributed to the phylum Pogonophora revealed the first symbiotic association of a metazoan with a chemosynthetic bacteria [15]. Such symbiotic associations were then evidenced in most of the vent taxa (see for a review [16]). In a paper on the role of the geothermal energy in sustaining these deep oases, Jannasch \& Mottl [17] concluded: "It is surprising that, as far as we know, science fiction writers did not turn their attention to geochemically supported complex forms of life until such forms were actually discovered in the deep sea."

The discovery of these bizarre ecosystems inhabited by large organisms with unusual feeding types revived the discussion about the antiquity of deep-sea fauna [17, 18]. Part of the newly discovered animals was classified into new higher taxonomic categories. This ranking into new families of even phyla was indeed a translation of the "antiquity" hypothesis: "the high level of endemism, at high taxonomic levels, associated with abyssal hydrothermal springs must be the result of a long and continuing evolutionary history" [18].

The discovery of cold seeps [20] showed that similar communities supported by a primary chemosynthetic production were also found in passive continental margins. In these habitats sulphiderich hypersaline waters were observed seeping out of the oceanic/continental crust without any notable elevation of temperature. Many of the higher taxa described as endemic to vents were also discovered at these cold seeps sites. It was latter shown that some of these taxa were also present on the carcasses of vertebrates and on plant remains sunken at the deep-sea floor [21, 22]. The taxa observed as associated with these organic remains were generally smalls and were known from the first deep-sea expedition but have been merely considered as zoological curiosities and remained poorly studied until the discovery of their close evolutionary relationships with vent and seeps animal ([23]). Little \& Vrijenhoek [24] re-examined the antiquity hypothesis using both fossil evidence and the available results in molecular phylogenies. Even if scarce and incomplete, both the available fossil data and phylogenetic results did not support this hypothesis. 


\section{ORIGINS}

\subsection{Hot vents metazoans and their systematics}

"Because of their unusual adult morphology the Vestimentifera (now recognized as members of the polychaete family Siboglinidae) were elevated to the phylum level, a rank that typically corresponds with an early Paleozoic origin." [25]. This citation summarizes the trends in the taxonomic treatments of vent organisms. In 1985, in a symposium paper, Newman [18] listed 58 species endemic to hot vents. Based on these 58 species, 33 new genera and 16 new family groups (super family, family or sub family) were described. The six species attributed to Vestimentifera were, following Jones [26], divided into six genera, four families and three orders and two classes! The major taxonomic changes for the taxa listed by Newman thirty years ago concerned the taxa classified in the Vestimentifera now considered as belonging to the Siboglinidae (see [27] for more details about this major taxonomic revision). Another major change was that many of the listed taxa were in fact not endemic to hot vents. For example the Siboglinidae now include species associated with hot vents, but also with cold seeps and organic falls. All the organisms included in this clade are gutless and are obligatory associated to bacterial symbionts. The discovery of the bone-eating worms Osedax [28], revealed that the symbiosis in Siboglinidae was not only with chemosynthetic bacteria but also with heterotrophic bacteria. The family is thus much diversified in deep-sea environments but not endemic to hot vents.

In 2005, Wolf [29] reexamined the diversity and endemism of hot vent taxa. He listed 609 species among which he considered 506 as strictly vent endemics and 35 as shared with seeps and whale or wood falls. These 609 species were attributed to 333 genera, 151 of which considered as hot vent endemics. Among the 185 families identified in this dataset 14 were considered as vent endemics (one Brachyura, two Cirripedia, three Copepoda, one Isopoda, four Gastropoda, one Hemichordata and two Polychetae families). Ten years later, the exploration of sunken whale and sunken wood habitats, and addition of data from cold seeps showed that at the family level the endemism associated with hot vents was much lower than what was estimated by Wolf [29]. Indeed, at least half of the families listed are also present at cold seeps and/or wood or whale falls or in other deep-sea habitats.

Such attributions of the species newly discovered at vents to new higher taxonomic entities was not restricted to the first years after the discovery of the first vents. For example, in 1998, the first octopod species potentially restricted to vents was described [30]. The species was attributed to a new genus and "The possibility of raising a new sub-family (Vulcanoctopodinae) Octopodidae, the ecology and adaptations of these vent animal are discussed." The most recent revision [31] showed that this species had a close affinity with two other species: Enteroctopus dolphei (the giant pacific octopus) and Muusoctopus normani (a genus of cold-water inkless octopus). Considering both molecular and morphological characters, these three genera are now attributed to a new family, the Enteroctopidae.

Alvinorarid shrimps provide another example of the taxonomic treatment of the species associated with hot vents. The first species, Alvinocaris lusca, was described from the sampling of the Galapagos vents, and attributed to a new genus of bresilid shrimps [32]. A new genus, Rimicaris, with two new species was then described from Mid-Atlantic hot vents [33] and a new family was proposed [34]. Presently 8 genera and about 27 species are attributed to this family and associated with hot vents and/or with cold seeps. Recently, two different species described respectively from vent or from seeps were shown to be genetically identical [35]. Recent phylogenetic analyses of caridean shrimps supported the robustness of the Alvinocarididae but suggested that there is a taxonomic inflation into the delimitation of so many genera (e.g. [36]).

\section{Insights on into the evolutionary origins of some flagship organisms}

"The existence of mesozoic remnants in current hydrothermal populations, together with the discovery of these fossilized tubes which appear to have belonged to forms closely related to the present day Pompeii worm, leads us to the conclusion that the hydrothermal populations are in fact very ancient. 
Research for analogous traces in Paleozoic deposits would also be of great interest." This citation from a review paper written by Laubier \& Desbruyères [37] summarizes the underlying hypothesis of most of the phylogenetic studies of vent organisms. Among the most amazing cases they notably pointed at the scalpellid barnacle Neolepas, described as a Mezosoic relic [38] and at the gastropod Neomphalus, described [39] as belonging to a new sub-order of gastropods deriving from their closer extinct relatives in the Mesozoic. They also pointed at the Bythograeidae crabs, which position within the Barchyuria (the true crabs which is the most diverse infra-order within Decapoda) is still unresolved. However, new fossil data, new molecular phylogenetic methods and extended taxonomic and ecological sampling completely revived the antiquity hypothesis.

The first results of molecular phylogenies were used to revisit the fossil data [24]. These pioneering studies did not only point at the recent origin of the taxa but also at their affinities with organisms from other habitats. Among these studies, Distel et al. [22] were the first to point at the close relationship among the giant mussels with chemosynthetic symbionts from vents and seeps with the small mussels associated with large organic falls (i.e. sunken whales carcasses and wood). This study showed that the Bathymodiolinae have a recent origin within mytilids and these giant chemosynbiotic deep-sea mussels were included in a clade that also included the small deep-sea mussels associated to organic remains. From this result the authors proposed the Wooden Stone hypothesis according to which whale carcasses and sunken wood were an evolutionary step toward the colonization of deep-sea cold seeps and hot vents. In this paper, the sole use of the $18 \mathrm{~S}$ gene provided no resolution within the detected clade. Nevertheless the authors suggested a basal position of wooden mussels. Following this paper, phylogenies analysed the evolution of habitat use in deep-sea mussels. Notably Jones et al. [39] added to the analysis several genes and more sophisticated methods and an extended taxonomic sampling. However, the taxonomic sampling mainly covered the giant mussels from vents and seeps and the only species associated with sunken wood was used to root the phylogenetic tree.

The addition of several species associated with sunken wood allowed showing that if part of the sunken wood species have indeed a basal position, the others belong to a clade that also include the giant mussels from vent and seeps [40]. The inclusion of more species from various deep-sea environments and the use of a multigene phylogeny finally showed that there are several independent lineages that include giant mussels [41]. This analysis confirmed that the ancestral habitat of the deepsea chemosynthetic mussels was on organic falls but suggested that the colonization of seeps and vent occurred several times independently.

This example illustrates that the phylogenetic analysis of vent organisms have been biased by strong a priori hypotheses that were often not tested because of poor taxonomic sampling (i.e. supposedly basal taxa were used to root phylogenetic trees). For example in a review paper van Dover et al. [42] used the paper of Distel et al. [22] to consider that "Bathymodiolid mussels diverged more recently from shallow-water, suspension-feeding mussels and diversified first as decomposers of wood and bone" although the analysis of Distel et al. did not reveal any relationship within the clade regrouping vent, seeps and organic fall mussels.

The evidence brought by fossil data was discussed in Vrijenhoek [25]. The fauna resembling the modern vent fauna appears between the middle Eocene in seep deposits but few data are available for Cenozoic vents and seeps [43]. Notably, the identification of worm tubes resembling that of modern vestimentiferan in Phanerozoic deposits remains controversial (e.g. [25, 44, 45]). Whatever the exact date of the apparition of the siboglinids, the family is however not endemic to vents. The most recent molecular results suggested that the diversification of the lineage occurred at vents and seeps first and then at whale falls (reviewed [46]). For many molluscan taxa, the fossil data are difficult to interpret because of convergent evolution and plasticity of the shell. The Neomphalidae were among the taxa pointed as potential Mesozoic relic [38]. Although the phylogenetic relationships and the taxonomic status of Vetigastropoda remain still poorly resolved, available data showed that the Neomphalidae are included in a clade (Neomphalina) that is not restricted to hot vents but in which some lineages or species 


\section{ORIGINS}

are also present at cold seeps and sunken woods [47]. Barnacles are among the flagship taxa considered in the antiquity hypothesis, notably by Newman [18] based on fossil evidences. Recent phylogenetic results showed major problems in the taxonomy of barnacles notably at higher classification levels [48]. A recent phylogenetic analysis of vent barnacles moreover showed two, relatively recent, independent invasions of vent environments [49].

\section{Conclusions and perspectives}

Even if almost 40 years after the discovery of the first hot vent on the Galapagos rift, many studies confirmed the evolutionary originality of most of the higher rank taxa identified by Newman [18] as endemic to vents, most revealed that these taxa are not restricted to hot vent environments and that they are much younger than first hypothesized. Among the enigmatic higher taxa endemic to vents, the phylogenetic position of Bythogaeidae among Brachyurian families [50] and the position of Alvinellidae within Terrebelomorph annelids [51] still remain unresolved. The exploration of the deep sea and inclusion of more ecological diversity in phylogenetic analyses allowed the renewal of the hypotheses about the origin of hydrothermal vents. The diversity in bathyal of abyssal area is still very poor and much exploration and research efforts are need to understand the "unique attributes of the world's largest ecosystem" [52]. The question of the origin of hydrothermal vent organisms should be place in the larger framework of the origin of deep-sea biodiversity (e.g. [49, 53, 54]). The main challenges are the sampling efforts, needed both to obtain adequate present and fossil evidences.

\section{References}

[1] T.R. Anderson, T. Rice, Endeavour 30(4), 131-137 (2006)

[2] A. Milne-Edwards, Annales des sciences naturelles, Zoologie (4) 15, 149-157 (1861)

[3] C.W. Thomson, General introduction to the zoological series of reports. In: Scientific results of the Voyage of HMS Challenger during the years 1873-1876. Zoology - Volume 1 (Thomson CW ed), 1-61 (1880)

[4] H.. Moseley, Nature 21, 543-547 (1880)

[5] R.J. Menzies, J. Imbrie, Oikos, 9(2), 192-210 (1958)

[6] M. Kelly, New Zealand Journal of Marine and Freshwater Research 37(1), 113-127 (2003)

[7] M.A. Schlacher-Hoenlinger, A. Pisera, J.N.A. Hooper, Zoosystema, 27(4), 649-698 (2005)

[8] L.A. Zenkevitch, J.A. Birstein, Deep Sea Research (1953), 7(1), 10-23 (1960)

[9] A.H. Clarke, On the composition, zoogeography, origin and age of the deep-sea mollusk fauna. In Deep Sea Research and Oceanographic Abstracts (Vol. 9, No. 7, pp. 291-306). Elsevier (1962, October)

[10] L.J. Corrigan, T. Horton, H. Fotherby, T.A. White, A.R. Hoelzel, Evolutionary Biology, 41(1), 154-165 (2014)

[11] J.J. Childress, Trends in Ecology \& Evolution, 10(1), 30-36 (1995)

[12] P. Lonsdale, Deep Sea Research, 24(9), 857-863 (1977)

[13] J.B. Corliss, J. Dymond, Science 203, 16 (1979)

[14] E.G. Ruby, C.O. Wirsen, H.W. Jannasch, Applied and environmental microbiology 42(2), 317-324 (1981)

[15] C.M. Cavanaugh, S.L. Gardiner, M.L. Jones, H.W. Jannasch, J.B. Waterbury, Science 213, 340-342 (1981)

[16] C.M. Cavanaugh, Z.P. McKiness, I.L. Newton, F.J. Stewart, Marine chemosynthetic symbioses. In The prokaryotes (pp. 475-507). (Springer, New York, 2006)

[17] H.W. Jannasch, M.J. Mottl, Science 229(4715), 717-725 (1985)

[18] W.A. Newman, Bulletin of the Biological Society of Washington 6, 231-242 (1985) 
[19] A.G. McArthur, V. Tunnicliffe, Geological Society, London, Special Publications 148(1), 271-291 (1998)

[20] C.K. Paull, B. Hecker, R. Commeau, R.P. Freeman-Lynde, C. Neumann, W.P. Corso, ..., J. Curray, Science 226(4677), 965-967 (1984)

[21] C.R. Smith, A.R. Baco, Oceanography and marine biology 41, 311-354 (2003)

[22] D.L. Distel, A.R. Baco, E. Chuang, W. Morrill, C. Cavanaugh, C.R. Smith, Nature, 403(6771), 725-726 (2000)

[23] S. Samadi, L. Corbari, J. Lorion, S. Hourdez, T. Haga, J. Dupont,..., B. Richer De Forges Cahiers de Biologie Marine, 51(4), 459 (2010)

[24] C.T. Little, R.C. Vrijenhoek, Trends in Ecology \& Evolution 18(11), 582-588 (2003)

[25] R.C. Vrijenhoek, DeepSea Research Part II: Tropical Studies in Oceanography 92, 189-200 (2013)

[26] M.L. Jones, Bulletin of the Biological Society of Washington 6, 117-158 (1985)

[27] F. Pleijel, T.G. Dahlgren, G.W. Rouse, Comptes rendus biologies 332(2), 140-148 (2009)

[28] G.W. Rouse, S.K. Goffredi, R.C. Vrijenhoek, Science 305(5684), 668-671 (2004)

[29] T. Wolff, CBM-Cahiers de Biologie Marine, 46(2), 97-104 (2005)

[30] A.F. González, A. Guerra, S. Pascual, P. Briand, Cahiers de biologie marine 39(2), 169-184 (1998)

[31] J.M Strugnell, M.D. Norman, M. Vecchione, M. Guzik, A.L. Allcock, Hydrobiologia 725(1), 215-235 (2014)

[32] A.B. Williams, F.A. Chace, Journal of Crustacean Biology 2(1), 136-147 (1982)

[33] A.B. Williams, P.A. Rona, Journal of Crustacean Biology 6(3), 446-462 (1986)

[34] M.L. Christoffersen, Boletim de Zoologia 10, 273-281 (1986)

[35] S. Teixeira, K. Olu, C. Decker, R.L. Cunha, S. Fuchs, S. Hourdez,..., S. Arnaud-Haond, Molecular ecology 22(18), 4663-4680 (2013)

[36] L. Aznar-Cormano, J. Brisset, T.Y. Chan, L. Corbari, N. Puillandre, J. Utge,..., S. Samadi, Genetica 1-11 (2015)

[37] L. Laubier, D. Desbruyères, Transactions of the San Diego Society of Natural History 19, 153-167 (1979)

[38] J.H. McLean, Malacologia 21(1-2), 291-336 (1981)

[39] W.J. Jones, Y.J. Won, P.A.Y. Maas, P.J. Smith, R.A. Lutz, R.C. Vrijenhoek, Marine Biology 148(4), 841-851 (2006)

[40] S. Samadi, E. Quéméré, J. Lorion, A. Tillier, R. von Cosel, P. Lopez,..., M.C. BoisselierDubayle, Comptes rendus biologies, 330(5), 446-456 (2007)

[41] J. Thubaut, N. Puillandre, B. Faure, C. Cruaud, S. Samadi, Ecology and evolution 3(14), 4748-4766 (2013)

[42] C.L. Van Dover, C.R. German, K.G. Speer, L.M. Parson, R.C. Vrijenhoek, Science 295(5558), 1253-1257 (2002)

[43] S. Kiel, The fossil record of vent and seep mollusks. In The vent and seep biota (pp. 255-277) (Springer Netherlands, 2010)

[44] A. Hilario, M. Capa, T.G. Dahlgren, K.M. Halanych, C.T. Little, D.J. Thornhill,..., A.G. Glover, PloS one 6(2), e16309 (2011)

[45] L. Parry, A. Tanner, J. Vinther, Palaeontology 57(6), 1091-1103 (2014)

[46] C.R. Smith, A.G. Glover, T. Treude, N.D. Higgs, D.J. Amon, Marine Science 7 (2015)

[47] M. Heß, F. Beck, H. Gensler, Y. Kano, S. Kiel, G. Haszprunar, Journal of Molluscan Studies 74(4), 383-401 (2008)

[48] M. Pérez-Losada, M. Harp, J.T. Høeg, Y. Achituv, D. Jones, H. Watanabe, K.A. Crandall, Molecular phylogenetics and evolution 46(1), 328-346 (2008)

[49] S. Herrera, H. Watanabe, T.M. Shank, Molecular ecology 24(3), 673-689 (2015) 


\section{ORIGINS}

[50] M. Mateos, L.A. Hurtado, C.A. Santamaria, V. Leignel, D. Guinot, PloS one 7(3), e32066 (2012)

[51] M. Zhong, B. Hansen, M. Nesnidal, A. Golombek, K.M. Halanych, T.H. Struck, BMC evolutionary biology 11(1), 369 (2011)

[52] E. Ramirez-Llodra, A. Brandt, R. Danovaro, B. De Mol, E. Escobar, C.R. German, .., M. Vecchione, Biogeosciences 7, 2851-2899 (2010)

[53] B. Thuy, S. Kiel, A. Dulai, A.S. Gale, A. Kroh, A.R. Lord, ..., M. Wisshak, Proceedings of the Royal Society B: Biological Sciences 281(1786), 201326244 (2014)

[54] S. Kiel, Proceedings of the Royal Society of London B: Biological Sciences 282(1804), 20142908 (2015) 